\title{
Obesidade na adolescência: um perfil traçado atualmente através de revisão
}

\section{narrativa}

\author{
Adolescent obesity: a profile currently outlined through narrative review
}

Obesidad adolescente: un perfil que se describe actualmente a través de una revisión narrativa

Recebido: 10/01/2021 | Revisado: 11/01/2021 |Aceito: 11/01/2021 | Publicado: 11/01/2021

Maciel Borges do Nascimento

ORCID: https://orcid.org/0000-0002-9190-6072 Centro Universitário UniAges, Brasil

E-mail: macielborges17@gmail.com

Murilo de Jesus Porto

ORCID: https://orcid.org/0000-0003-2339-8173

Universidade do Estado da Bahia, Brasil

E-mail: murilo.porto@hotmail.com Jaciara Pinheiro de Souza

ORCID: https://orcid.org/0000-0002-4056-974X

Centro Universitário UniAges, Brasil

E-mail: jacipinheirosouza@hotmail.com

Maria de Fátima Santana de Souza Guerra

ORCID: https://orcid.org/0000-0002-2760-8230

Centro Universitário UniAges, Brasil

E-mail: marinaide10@gmail.com

Ana Mara Borges Araujo

ORCID: https://orcid.org/0000-0003-4065-241X

Centro Universitário UniAges, Brasil

E-mail: anamaraborges_@hotmail.com

Walber Barbosa de Andrade

ORCID: https://orcid.org/0000-0003-0290-5009

Centro Universitário UniAges, Brasil

E-mail: blekwalber@hotmail.com

Welde Natan Borges de Santana

ORCID: https://orcid.org/0000-0001-9781-2934

Centro Universitário UniAges, Brasil

E-mail:welder_natan@hotmail.com

Gilvania Piedade Santos

ORCID: https://orcid.org/0000-0003-2435-0198

Centro Universitário UniAges, Brasil

E-mail: gilvania.piedade@gmail.com

Antero Fontes de Santana

ORCID: https://orcid.org/0000-0002-8944-3216

Centro Universitário UniAges, Brasil

E-mail: anterosantana@hotmail.com

Sandra Regina Santana Silva

ORCID: https://orcid.org/0000-0002-8218-3407

Centro Universitário UniAges, Brasil

E-mail: sandrareginaenfa@hotmail.com

\section{Resumo}

A obesidade consiste em uma condição clínica caracterizada pelo acúmulo excessivo de gordura no organismo, considerada uma doença genética multifatorial, agravadas por fatores ambientais, psicológicas, culturais, hereditários, alimentares, hormonais e metabólicos. A presente pesquisa tem como objetivo discutir sobre a obesidade na adolescência em período escolar através de uma revisão literatura. Como processo metodológico, tratra-se de um estudo de revisão narrativa simples. A coleta de dados para a realização deste estudo foi feito a partir de um levantamento bibliográfico através de busca eletrônica de artigos indexados no Scielo, Google Acadêmico, Lilacs, sites confiáveis, manuais do Ministério da Saúde. Como resutados apresentados, pode-se notar que, nos últimos anos, 
houve um grande número de casos de obesidade na infância e na adolescência. Várias pesquisas apontam que este crescimento repentino da obesidade pode estar associado com diversos fatores contribuintes como: maus hábitos alimentares, sedentarismo, fatores genéticos, nível socioeconômico e fatores emocionais. Estudos mostram que fatores genéticos têm grande influência no aumento da obesidade, sendo ela uma doença complexa e heterogênea. É importante ressaltar que fatores genéticos por si só não explicam o ganho de peso. Dessarte, a combinação de genes com os fatores supramencionados estão envolvidos no desenvolvimento das formas mais comuns da obesidade. Vários tratamentos foram mencionados durante essa revisão, sendo que a atividade física na adolescência juntamente com a MEV têm seu papel fundamental no tratamento e prevenção da obesidade.

Palavras-chave: Obesidade; Adolescentes; Revisão narrativa.

\begin{abstract}
Obesity is a clinical condition characterized by excessive accumulation of fat in the body, considered a multifactorial genetic disease, aggravated by environmental, psychological, cultural, hereditary, dietary, hormonal and metabolic factors. This research aims to discuss obesity in adolescence during school years through a literature review. As a methodological process, it is a simple narrative review study. The data collection for this study was made from a bibliographic survey through electronic search of articles indexed in Scielo, Google Scholar, Lilacs, reliable sites, Ministry of Health manuals. As results presented, it can be noted that, in recent years, there has been a large number of cases of obesity in childhood and adolescence. Several researches point out that this sudden increase in obesity may be associated with several contributing factors such as: bad eating habits, physical inactivity, genetic factors, socioeconomic level and emotional factors. Studies show that genetic factors have a major influence on the increase in obesity, which is a complex and heterogeneous disease. It is important to note that genetic factors alone do not explain weight gain. Thus, the combination of genes with the factors mentioned above are involved in the development of the most common forms of obesity. Several treatments were mentioned during this review, with physical activity in adolescence together with SEM having a fundamental role in the treatment and prevention of obesity.
\end{abstract}

Keywords: Obesity; Adolescents; Narrative review.

\title{
Resumen
}

La obesidad es una condición clínica caracterizada por la acumulación excesiva de grasa en el cuerpo, considerada una enfermedad genética multifactorial, agravada por factores ambientales, psicológicos, culturales, hereditarios, dietéticos, hormonales y metabólicos. Esta investigación tiene como objetivo discutir la obesidad en la adolescencia durante los años escolares a través de una revisión de la literatura. Como proceso metodológico, es un simple estudio de revisión narrativa. La recolección de datos para este estudio se realizó a partir de una encuesta bibliográfica mediante búsqueda electrónica de artículos indexados en Scielo, Google Scholar, Lilacs, sitios confiables, manuales del Ministerio de Salud. Como resultados presentados, se puede notar que, en los últimos años ha habido un gran número de casos de obesidad en la infancia y la adolescencia. Varias investigaciones señalan que este aumento repentino de la obesidad puede estar asociado a varios factores coadyuvantes como: malos hábitos alimenticios, inactividad física, factores genéticos, nivel socioeconómico y factores emocionales. Los estudios demuestran que los factores genéticos tienen una gran influencia en el aumento de la obesidad, que es una enfermedad compleja y heterogénea. Es importante señalar que los factores genéticos por sí solos no explican el aumento de peso. Así, la combinación de genes con los factores antes mencionados están implicados en el desarrollo de las formas más comunes de obesidad. Durante esta revisión se mencionaron varios tratamientos, teniendo la actividad física en la adolescencia junto con el SEM un papel fundamental en el tratamiento y prevención de la obesidad.

Palabras clave: Obesidad; Adolescentes; Revisión narrativa.

\section{Introdução}

A nutrição é um dos principais fatores para o desenvolvimento biopsicossocial do indivíduo; assim como na prevenção e promoção de saúde. Neste sentido, muitos aspectos influenciam para a escolha dos alimentos: hábitos, fatores sociais, educacionais, psicológicos e as condições agônicas. Como em todas as etapas da vida a alimentação difere de cada indivíduo, logo, podemos destacar que a adolescência ocorre intensas mudanças físicas e psicológicas, influenciadas por fatores genéticos, fatores estes que contribuem para vulnerabilidade característica desse grupo populacional (Senac, 2008).

Assim os adolescentes podem ser considerados um grupo de risco nutricional, devido a inadequação de sua dieta e o aumento das necessidades e nutrientes para suprir a demanda da fase do crescimento. Vale ressaltar, que as condições sociais e ambientais influenciam no estilo alimentar dos adolescente. Não podemos deixar de abordar a atuação da mídia, já que as exibições de imagens nas propagandas de TV são capazes de influenciar esta faixa etária na qualidade da alimentação, sendo 
que grande parte dos produtos industrializados "produtos da publicidade" veicula alimentos com grande valor de gordura e alto teor calórico, provocando o acúmulo de gordura e, muitas das vezes, a obesidade (Enes, 2010).

Atualmente, as crianças e os adolescentes permanecem com mais frequência assistindo TV, fator que influencia na prevalência de excesso de peso devido à falta de atividades físicas, conduzindo-os ao sedentarismo (Enes, 2010). De acordo com a Sociedade Brasileira de Pediatria (SBP) (2012), a adolescência é uma fase da vida crítica para o desenvolvimento da obesidade, no entanto, é preocupante o aumento da prevalência de sobrepeso e obesidade nessa fase, relacionado às complicações que podem vim desencadear como: problemas metabólicos; cardiovasculares; pulmonares; ortopédicas; e formação de câncer na fase adulta decorrente da obesidade, afirma SBP (2012). Neste sentido, a presente pesquisa tem como objetivo discutir sobre a obesidade na adolescência em período escolar através de uma revisão narrativa.

\section{Metodologia}

Tratra-se de um estudo de revisão narrativa simples, com metodologia adotada para a coleta de dados para a realização deste estudo foi um levantamento bibliográfico através de busca eletrônica de artigos indexados no Scielo, Google Acadêmico, Lilacs, sites confiáveis, manuais do Ministério da Saúde, a partir das palavras - chaves: Obesidade; adolescência.

A presente pesquisa é de caráter qualitativo, que busca, sobretudo, a análise a partir de dados que tenham como relevância a qualidade das informações. Segundo, Bógus e Martins (2004), a pesquisa qualitativa busca entender o particular do estudo. Na pesquisa qualitativa o pesquisador interpreta as correlações casuais através da descrição, ao invés de métodos estatísticos (Gil, 2012).

Foram utilizados como critérios de inclusão:

- Veículo de publicação: artigos e dissertações;

- Idioma de publicação: português;

- Referências que tiveram como objetivos: o estudo voltado para obesidade na adolescência no período escolar.

Como critérios de exclusão:

- Trabalhos que abordassem a obesidade em públicos diferentes do estudado (adolescente);

- Trabalhos incompletos;

- Trabalhos repetidos;

- Pesquisa que cobrasse pelo acesso.

\section{Resultados e Discussão}

\section{Etiologia Da Obesidade}

A palavra "obesidade" tem a sua origem etimológica no latim obesîtas (âtis - gordura excessiva) que caracteriza o indivíduo gordo, com excessivo volume do ventre e de outras partes do corpo (Pereira \& Lopes, 2012).

A definição de obesidade consiste em uma condição clínica caracterizada pelo acúmulo excessivo de gordura no organismo, bem como podendo ser considerada um uma doença genética multifatorial, agravadas por fatores ambientais, psicológicas, culturais, hereditários, alimentares, hormonais e metabólicos (Domingues, 2006).

Ainda este mesmo autor define a obesidade como sobrepeso corporal que excede do peso normal dos indivíduos da mesma raça, sexo, idade e constituição física. A obesidade pode ser considerada um distúrbio no estado nutricional, provocado por um desequilíbrio prolongado e/ou permanente entre a ingestão e o gasto calórico. O excesso de peso, por seu lado, é definido como um peso corporal que excede o peso normal ou padrão de uma determinada pessoa, baseando-se na sua altura e constituição física (Pereira \& Lopes, 2012). 


\section{Obesidade na adolescência}

De acordo com a OMS, adolescência corresponde ao período de 10 a 19 anos, logo pode ser dividida em duas fases: a primeira dos 10 aos 14 anos (Pré-adolescência), que por sua vez, dá início as mudanças puberais; e a segunda dos 15 aos 19 anos, quando termina a fase de crescimento e de desenvolvimento morfológico.

A adolescência por sua vez, consiste em um período de crescimento e de mudanças de hábitos. Brunner \& Suddart (2005) classificam a adolescência como uma fase de mudanças, sendo de hábitos alimentares, como comportamentos, que afetam diretamente na qualidade nutricional. Portanto a análise e avaliação nutricional nesta fase são fundamentais (Brunner \& Suddart, 2005).

É notável que as crianças e adolescentes são influenciados pela mídia, mediante a este fator, estudos mostram, segundo dados da Pesquisa de Orçamentos Familiares (POF/IBGE), realizada entre 2002 e 2003 pelo Ministério da Saúde, que $16,7 \%$ das crianças e adolescentes entre 10 e 19 anos têm excesso de peso e, destes, 2,3\% estão obesos.

\section{Aspectos fisiológicos do tecido adiposo}

O sentido fisiológico do acúmulo de gordura tem, como principal função, a capacidade de guardar energia para desenvolvimento das atividades e isolante térmico, que por sua vez, advém de uma herança evolutiva que tem como objetivo a sobrevivência dos seres humanos, afirma Teixeira (2012).

No entanto, na atualidade o homem deixa de realizar atividades vigorosas, diferente da pré-história, no qual o homem com seu biótipo dotado de força era o caçador, objetivando através desta prática a alimentação da prole. O homem moderno é restrito a desempenhar atividades com pouca movimentação corporal, logo não há o grande gasto de energia que outra necessitaria, culminando no estoque excessivo de gordura (Varella, 2006).

Além disso, o modo de obter os alimentos e os hábitos alimentares mudaram. O homem primitivo caçava seu próprio alimento, o que gerava o gasto de energia, e consumia alimentos naturais ligado principalmente a frutas, ervas e carnes frescas (Varella, 2006).

Em contrapartida, a modernidade trouxe a disponibilização de redes de supermercados, comércios e afins, que disponibilizam alimentos. E a indústria alimentícia, construiu através de alimentos naturais e inúmeras substâncias laboratoriais, vários produtos alimentícios, hipercalóricos e hipossódicos. A urbanização e seu impacto nos padrões de alimentação e a falta de atividade física contribuíram para a evolução do excesso de peso e, consequentemente, para as mudanças dos indicadores nutricionais (Velásquez-Meléndez et al, 2004).

\section{Aspectos fisiopatológicos do tecido adiposo}

Toda e qualquer doença é desencadeada através de um processo distinto de fisiopatologia. Logo, para discutirmos sobre a obesidade em qualquer grupo afetado, é de suma relevância compreender os processos culminantes na irregularidade fisiológica. Neste sentido, cabe ressaltar que desde nosso processo de formação humana, ocorrem mudanças com o tecido adiposo. A sua formação ocorre até a $8^{\mathrm{a}}$ semana embrionária, assim como os demais tecidos. $\mathrm{Na} 15^{\mathrm{a}}$ semana de vida intrauterina, ocorre a hiperplasia dos adipócitos, células que constituem o tecido adiposo, que se estende até os dois anos de vida. E nos anos seguintes seu desenvolvimento ocorre de maneira branda até os 10 anos de idade. Após tal faixa etária, a hiperplasia volta a aumentar, principalmente no sexo feminino (Marcondes, 2002).

Neste sentido, de acordo com Teixeira (2012), no momento do nascimento, o corpo humano contém cerca de $12 \%$ de gordura, e logo no período neonatal, esse valor pode chegar em $25 \%$. Posteriormente ocorre um diminuição cerca de $15 \%$ a $18 \%$, do tecido adiposo, até o início da puberdade. Destarte, a importância de discutir a obesidade nos pré-adolescentes (9 a 14 anos). 
Os estoques de gordura no organismo são regulados pela ingestão de calorias e pelo gasto energético. Deste modo, Quando há equilíbrio entre a ingestão alimentar e o gasto energético, os padrões fisiológicos são mantidos e também o peso corporal. Em contrapartida, o desequilíbrio, voltado para a ingestão alimentar alta, e o pouco gasto energético levará ao processo de acúmulo de gordura, e progressivamente à obesidade. A modernidade, trouxe impacto nos padrões de alimentação e a falta de atividade física, assim contribuíram para a evolução do excesso de peso e, consequentemente, para as mudanças dos indicadores nutricionais (Velásquez-Meléndez et al, 2004).

Os indicadores apontam o aumento crescente de obesos e os estudiosos começaram a estudar os processos fisiopatológicos desencadeante da patologia. Inúmeros mecanismos estariam envolvidos neste distúrbio, contudo ainda não há clareza com relação ao processo completo da fisiopatologia Warden, Wander (1997). Todavia, as pesquisas no geral seguem dois eixos centrais da biologia molecular: a leptina e o neuropeptídio Y, cujos mecanismos já estão bem estabelecidos (Sánchez, 1997).

Tais componentes seriam regulados por inúmeros genes que participam da regulação do peso corporal (Warden e Wander, 1997). Sendo que, a leptina é considerado um hormônio peptídico com 167 aminoácidos secretado principalmente pelo tecido adiposo, e em menor grau pelo tecido hipotalâmico, medula óssea e estômago. Ela atua como produtora do sinal de saciedade aferente em um circuito de feedback, e suas proporções de concentração seria de acordo com o volume de células adiposas (Maffei, 1995).

Logo, hipóteses sugerem que as mutações em genes fazem com que ocorra a produção de leptinas não ativas, fazendo com que não haja o sinal para a saciedade. Assim, o indivíduo comerá além do que seu corpo necessite, ocorrendo o acúmulo de gordura nos adipócitos (Chen et al, 1996).

Contudo, pode ser que a leptina seja produzida de maneira normal, e surja alguma alteração no receptor da leptina, deixando-os resistente a sua ação. Esse processo interfere no desencadeamento do sinal de saciedade, deixando o indivíduo com vontade de ingerir mais alimentos e ganhando peso excessivamente (Chen et al, 1996). Então como mecanismo de compensação, o organismo produz mais leptina para amenizar o erro fisiológico, no entanto não ocorre a sua ação desejada. Por isso, os obesos apresentam níveis séricos aumentados de leptina (Considine Et Al, 1996).

Enquanto a neuropeptídio Y (NPY) é um neurotransmissor importante no controle do peso corporal liberado pelos neurônios do hipotálamo. A sua função diferente da leptina, é desencadear a fome. E sua inibição, diminui o apetite e aumenta a termogênese pela ativação do sistema nervoso simpático (Campfield et al, 1995). E sua ação está diretamente ligada a leptina, ambas são antagonistas. Logo, a deficiência de leptina (mutação no gene da leptina) ou a resistência à ação da leptina (mutação no gene do receptor de leptina) culminará no aumento do NPY no hipotálamo (Campfield et al, 1995). E este neurotransmissor atuará no aumentando do apetite. Além disso, causa também hipersecreção de insulina e de glicocorticoides. Posteriormente serão produzidas mais leptina, no entanto a sua ineficácia não fará baixar os níveis de NPY. Assim, um círculo vicioso advindo do genótipo, desencadeará em um fenótipo do acúmulo de gordura corporal, advindo de umas pessoas que ingerem alimentos excessivamente, tornando-se obesidade (Green et al, 1995, Schwartz 2000 \& Haynes 1994).

\section{Tratamento Clínico}

Sabe-se que a melhoria na qualidade de vida são fatores para a diminuição da morbidade e a mortalidade de pacientes obesos. Entretanto, deve-se questionar a relação entre redução de peso e de gordura corporal, os quais, na maioria das vezes, são utilizados como sinônimos de forma errônea.

Diversos estudos mostram que a obesidade pode ser tratada apenas com a Mudança no Estilo de Vida (MEV), neste sentido, conforme Brasil (2006), o tratamento da obesidade consiste em uma dieta alimentar associado à prática de atividade física, e mudança de hábitos de vida. Assim, esta mudança tem como principal objetivo reduzir a gordura corporal. Essas 
mudanças devem ser observadas e indicadas de acordo com o sexo, a idade, condições de vida de cada indivíduo, bem como a saúde (Brasil, 2006).

\section{Tratamento Dietético}

Muitas das vezes, o tratamento dietético consiste em uma das melhores formas para saúde do paciente. Dessa forma, quando há essa mudança aliada com o gasto energético e mudança de comportamento, o tratamento é eficaz. O tratamento dietético só é bem sucedido, quando ocorre mudanças por toda a vida. De acordo com Brasil (2006), as dietas artificiais e rígidas, muitas das vezes, não são eficazes, mas quando agregado a um bom planejamento alimentar, obtém-se sucesso satisfatório (Brasil, 2006).

\section{Tratamento Farmacológico}

Quando se fala em tratamento farmacológico são utilizadas duas classe de fármacos: o anoréxico (fentermina e sibutramina) e o inibidor de lipase (orlistate), afirma Howland (2007).

Seguindo este contexto, conforme autor supracitado, para indicação deste tratamento deve ser adotados avaliação do IMC: <30 com presença de comorbidades; ou com dificuldade em perda de peso sem o tratamento farmacológico (Howland, 2007).

\section{Tratamento Cirúrgico}

Este tratamento é indicado quando o IMC é igual ou superior a 45, associa-se a diminuição da expectativa de vida e aumento da mortalidade por causa cardiovascular, podendo chegar a $90 \%$ em grandes obesos. No entanto, a cirurgia bariátrica (CB) é um recurso consistente nos casos de obesidade grave com falha de tratamento clínico, proporcionando aos pacientes redução nos índices de mortalidade e melhora de comorbidades clínicas, como se demonstrou em estudo observacional de dez anos de seguimento (Abeso, 2009). De acordo com ABESO , 2009 as indicações adotadas pelo Ministério da Saúde para realizar CB constam na Figura 1, que por sua vez são válidas para adultos entre 18 e 65 anos.

Figura 1 - Critérios de Indicação para cirurgia bariátrica.

Tabela 1 - Critérios de indicaçāo para cirurgia bariátrica ${ }^{67.17}$

\begin{tabular}{l} 
Adultos com IMC $\geq 40 \mathrm{~kg} / \mathrm{m}^{2}$ sem comorbidades (A) \\
\hline Adultos com IMC $\geq 35 \mathrm{~kg} / \mathrm{m}^{2}$ com uma ou mais comorbidades associadas (A)
\end{tabular}

Resistência aos tratamentos conservadores realizados regularmente há pelo menos dois anos (dietoterapia, psicoterapia, tratamento farmacológico e atividade física) (A) Motivação, aceitação e conhecimento sobre os riscos da cirurgia (A) Ausência de contraindicaçōes (A)

Fonte: Abeso (2009, p. 75). 


\section{Diagnóstico}

O diagnóstico de obesidade, de acordo com a Organização Mundial de Saúde é feito através do IMC, que é calculado pela seguinte fórmula: $\mathrm{IMC}=$ peso em $\mathrm{kg} \div(\text { altura em metro })^{2}$.

Uma vez avaliado o resultado, pode-se diagnosticar a obesidade quando os valores apresentar acima do indicado para a faixa etária, sexo e constituição física.

No entanto, segundo Brasil (2014) o IMC infantil é calculado de forma diferente da fórmula usada pelos adultos, levando em consideração que as crianças quando nascem naturalmente começam a vida com um alto índice de gordura, mas vão ficando mais magras conforme envelhecem. Desta forma, foi criado uma fórmula diferente para o cálculo do IMC que leva em consideração a idade da criança e também o sexo, já que influenciam no resultado. Segundo Brasil (2014) os valores de IMC variam de idade e sexo, conforme Figura 2:

Figura 2 - IMC Crianças e adolescentes do sexo masculino e feminino de 10 a 20 anos.

\begin{tabular}{|c|c|c|c|c|c|c|c|c|c|}
\hline \multirow[b]{2}{*}{$\begin{array}{l}\text { Idade } \\
\text { em } \\
\text { anos* }\end{array}$} & \multicolumn{2}{|c|}{ Meninos } & \multicolumn{2}{|c|}{ Meninas } & \multicolumn{2}{|c|}{ Meninos } & \multicolumn{2}{|c|}{ Meninas } & \multirow[b]{2}{*}{ Obesidade } \\
\hline & Sobrepeso & Obesidade & Sobrepeso & Obesidade & $\begin{array}{c}\text { Idade } \\
\text { em } \\
\text { anos* }\end{array}$ & Sobrepeso & Obesidade & Sobrepeso & \\
\hline 10 & 18,48 & 21,40 & 19,03 & 22,57 & 15,5 & 23,12 & 27,44 & 23,83 & 28,58 \\
\hline 10,5 & 18,81 & 21,91 & 19,43 & 23,13 & 16 & 23,53 & 27,87 & 24,10 & 28,87 \\
\hline 11 & 19,16 & 22,45 & 19,86 & 23,72 & 16,5 & 23,91 & 28,27 & 24,32 & 29,11 \\
\hline 11,5 & 19,54 & 23,01 & 20,32 & 24,34 & 17 & 24,27 & 28,63 & 24,50 & 29,28 \\
\hline 12 & 19,95 & 23,58 & 20,81 & 24,97 & 17,5 & 24,60 & 28,95 & 24,65 & 29,42 \\
\hline 12,5 & 20,38 & 24,16 & 21,31 & 25,60 & 18 & 24,91 & 29,24 & 24,77 & 29,52 \\
\hline 13 & 20,83 & 24,76 & 21,80 & 26,21 & 18,5 & 25,19 & 29,50 & 24,87 & 29,60 \\
\hline 13,5 & 21,30 & 25,35 & 22,28 & 26,79 & 19 & 25,45 & 29,72 & 24,97 & 29,67 \\
\hline 14 & 21,77 & 25,92 & 22,73 & 27,32 & 19,5 & 25,45 & 29,72 & 24,97 & 29,67 \\
\hline 14,5 & 22,23 & 26,46 & 23,15 & 27,80 & 20 & 25,45 & 29,72 & 24,97 & 29,67 \\
\hline 15 & 22,68 & 26,97 & 23,51 & 28,22 & & & & & \\
\hline
\end{tabular}

Fonte: OMS, 2007.

Partindo deste pressuposto, segundo Souza e Oliveira (2008), outro fator importante que deve ser investigado é a distribuição da gordura no corpo do indivíduo já que pode está diretamente relacionada com a saúde, principalmente, quando fica localizada na região abdominal. Dessarte, para avaliar esta relação entre a distribuição da gordura e o risco para outras doenças se utiliza a relação cintura/quadril (RCQ) que está por sua vez é a relação entre variáveis antropométricas de cintura e quadril. A expressão matemática é calculada dividindo o valor da circunferência da cintura (em centímetros) pelo valor da circunferência do quadril (em centímetros). Esta ferramenta é de muita importância para obter o diagnóstico de obesidade (Souza \& Oliveira, 2008).

No entanto, conforme o autor supracitado, o RCQ considera-se o melhor indicador de obesidade abdominal. Este índice é amplamente utilizado como um indicador de risco à saúde. A expressão matemática é calculada dividindo o valor da circunferência da cintura (em centímetros) pelo valor da circunferência do quadril (em centímetros). 


\section{Considerações Finais}

Pode-se notar que, nos últimos anos, houve um grande número de casos de obesidade na infância e na adolescência. Várias pesquisas apontam que este crescimento repentino da obesidade pode estar associado com diversos fatores contribuintes como: maus hábitos alimentares, sedentarismo, fatores genéticos, nível socioeconômico e fatores emocionais, conforme a revisão narrativa.

Estudos mostram que fatores genéticos têm grande influência no aumento da obesidade, sendo ela uma doença complexa e heterogênea, sofrendo influência de vários genes, os quais muitos ainda não foram determinados. É importante ressaltar que fatores genéticos por si só não explicam o ganho de peso. Dessarte, a combinação de genes com os fatores supramencionados estão envolvidos no desenvolvimento das formas mais comuns da obesidade.

Vários tratamentos foram mencionados durante essa revisão, sendo que a atividade física na adolescência juntamente com a MEV têm seu papel fundamental no tratamento e prevenção da obesidade, já que aceleram a perda de peso e o aumento da massa muscular, ajudando a reduzir os níveis de gordura no peso corpóreo.

Outro ponto importante, é que deve-se levar em consideração o nível socioeconômico e educacional do adolescente e de sua família, pois estes resultam em padrões de comportamento que afetam a ingestão calórica, o gasto energético e a taxa de metabolismo. Essa revisão narrativa contribuirá para ampliar as discussões a respeito da obesidade na adolescência, já que essa doença desencadeia vários problemas biopsicossocial, frequentemente, afetando o desempenho escolar e os relacionamentos sociais.

\section{Referências}

Abeso. (2009). Associação Brasileira para o Estudo da Obesidade e da Síndrome Metabólica Diretrizes brasileiras de obesidade 2009/2010 - Associação Brasileira para o Estudo da Obesidade e da Síndrome Metabólica. (3a ed.), AC Farmacêutica.

Brasil - Ministério da Saúde. (2006). Secretaria de Atenção à Saúde. Departamento de Atenção Básica. Obesidade. - Brasília: Ministério da Saúde.

Brunenr \& Suddar. (2005). Tratado de Enfermagem Médico- Cirúrgico. Guanabara Koogan.

Campfield, L. A., Smith, F. J., Guisez, Y., Devos, R., \& Burn, P. (1995). Recombinant mouse OB protein: evidence for a peripheral signal linking adiposity and central neural networks. Comment in: Science; 269(5223):475-6.

Chen, H., Charlat, O., Tartaglia, L. A., Woolf, E. A., Weng, X., \& Ellis, S. (1996). Evidence that the gene encodes the leptin receptor: Indentification of a mutation in the leptin receptor gene in $\mathrm{db} / \mathrm{db}$ mice. Cell; $84: 491-5$.

Considine, R. V., Sinha, M. K., Heilman, M. L., Kriavuciunas, A., Stephens, T. W., \& Nyce, M. R. (1996). Serum immunoreactive-leptin concentrations in normal-weigth and obese humans. $N$ Engl J Med; 334:292-95. Development of waist circumference percentiles in British children aged 5.0-16.9

Domingues, T., Oliveira, L. N. (2006). Obesidade Infantil e Suas Complicações: assistência de enfermagem. Ver Enferm UNISA; 7,57-9

Enes C., Slater C. B. (2010). Obesidade na adolescência e seus principais fatores determinantes. Rev Bras Epidemiol; 13(1), 163-71

Gil, A. C. (2012). Métodos e Técnicas de Pesquisas Social. (6a ed.), Altas.

Green Ed, M. M., Braden, V. V, Proenca, R., Silva, U., Zhang, Y. (1995). The human obese (OB) gene: RNA expression pattern and mapping on the physical, cytogenetic, and genetic maps of chromosome 7. Genome Res; 5(1).

Howlend, R. D. (2007). Farmacologia Ilustrada: Tradução Augusto Longeloh. Artmed.

Haynes, R. B. (1994). Developing optimal search strategies for detecting clinically sound studies in medline. Journal of the American Medical Informatics Association: JAMIA, 1(6), 447-458.

Maffei, M., Halaas, J., Ravussin, E., Pratley, R. E., Lee, G. H., \& Zhang, Y. (1995). Leptin levels in human and rodent: measurement of plasma leptin and ob RNA in obese and weight-reduced subjects. Nat Med; 1(11), 1155-61.

Marcondes, E. et al. (2002). Obesidade. In: Pediatria Básica, Tomo I- Pediatria Geral e Neonatal. (9a ed.), Sarvier, $682-686$.

Pereira, P. J. A., \& Lopes, L. S. C. (2012). Obesidade Infantil: Estudo Em Crianças Num Atl. Millenium. 105-125.

Sánchez, M. B. (1997). Genes y obesidad. An Esp Pediatr; 46, 1-2 
Research, Society and Development, v. 10, n. 1, e26710111857, 2021 (CC BY 4.0) | ISSN 2525-3409 | DOI: http://dx.doi.org/10.33448/rsd-v10i1.11857

Sbp-Sociedade Brasileira de Pediatria. (2012). Obesidade na infância e adolescência - Manual de Orientação / Sociedade Brasileira de Pediatria. Departamento Científi co de Nutrologia. (2a ed.), SBP.

Schwartz, M. W., Woods, S. C., Porte, D. Jr., Seeley, R. J., \& Baskin, D. G. (2000). Central nervous system control of food intake. Nature; 404(6778), 661-71. Review.

Senac, D. C. (2008) Nutrição e dietética. (2a ed.), Atual: editora Senac Nacional.

Souza, N. P. P., Oliveira, M. R. M. (2008). O ambiente como elemento determinante da obesidade. Rev Simbio-Logias; 1(1), 159-62

Teixeira Neto, F. (2009). Nutrição Clínica. Guanabara Koagon.

Valle, J. M. N., \& Euclydes, M. P. (2007). A formação dos hábitos alimentares na infância: uma revisão de alguns aspectos abordados na literatura nos últimos dez anos. Revista APS, 10(1), 56-65.

Varella, D. (2006). Borboleta da alma: escrito sobre ciência e saúde. Companhia das letras.

Velásquez-Meléndez, G., \& Pimenta, A. M. (2004). Epidemiologia do sobrepeso e da obesidade e seus fatores determinantes em Belo Horizonte (MG), Brasil: estudo transversal de base populacional. Ver Panam Salud Publica; 16(5), 308-14.

Warden, N. S., \& Wander, C. H. (1997). Pediatric obesity: An overview of etiology and treatment. Pediatr Clin North Am; 4, 339-61. y." European journal of clinical nutrition 55.10 (2001), 902-907. 